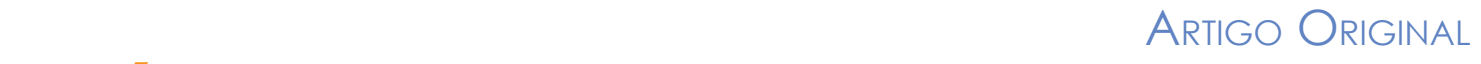 Análise da queda da audiência do Jornal Nacional e os impactos no telejornalismo
}

Analysis of the Jornal NaCional aUdience drop and the ImpaCtS ON NEWSCASt

\section{Valdecir Becker}

Professor do Programa de Pós-Graduação em Jornalismo da Universidade Federal da Paraíba.

E-mail: valdecir@ci.ufpb.br

Kellyanne Carvalho Alves

Doutoranda do Programa de Pós-Graduação em Comunicação da Universidade Federal de Pernambuco. E-mail: kellyanne@lavid.ufpb.br

Recebido em 30 de abril de 2015. Aprovado em 3 de julho de 2015.

\section{Resumo}

Este artigo faz uma análise sistemática da queda da audiência do Jornal Nacional, principal telejornal da televisão brasileira. A partir da análise estatística e da investigação empírica dos índices de audiência no período de 2000 a 2013, o artigo quantifica em $33,5 \%$ a queda da audiência do Jornal Nacional nesse período, faz comparações com os demais canais, cujas audiências também caíram, analisa padrões de variação e apresenta projeções para a audiência nos próximos 14 anos. Finalmente, propõe hipóteses para o impacto no telejornalismo, que atualmente enfrenta crises de identidade e de credibilidade.

Palavras-chave: Análise da audiência. Jornal Nacional. Projeção, impactos no telejornalismo.

\begin{abstract}
This article makes a systematic analysis of the audience drop of Jornal Nacional, the main news program of Brazilian television. From the statistical analysis and empirical investigation of the audience ratings between 2000 and 2013, the article quantifies the audience drop as being of $33.5 \%$, makes comparisons with other channels, whose audiences also dropped, analyzes patterns of variation and presents projections for the audience in the next 14 years. Lastly, it proposes hypotheses for the impact on newscast, which currently face identity and credibility crises.
\end{abstract}

Keywords: Audience analysis. Jornal Nacional. Projection, impacts on newscast. 


\section{Introdução}

Em 31 de dezembro de 2013, o maior telejornal da televisão brasileira, o Jornal Nacional (JN) registrou 19 pontos de audiência, menor índice já registrado, desde $1^{\circ}$ de setembro de 1969, quando a primeira edição do telejornal foi ao ar. Este número é sintomático, por representar uma queda sistemática da audiência, não apenas do telejornal, mas de toda televisão brasileira.

No Brasil virou senso comum de que a população se informa e se entretém pela televisão, que cobre praticamente todo território nacional e tem audiência inalcançável para qualquer outra mídia (BUCCI, 1997; MACHADO, 1996; HOINEFF, 2001). Por isso, a perda sistemática da audiência tem impactos em toda sociedade. Do ponto de vista comercial, a televisão aberta praticamente monopoliza a verba publicitária, recebendo 66,5\% de todo investimento (PROJETO INTER-MEIOS, 2013). Em outra palavras, a cada $\mathrm{R} \$ 100,00$ gastos com publicidade no Brasil, $\mathrm{R} \$ 66,50$ vão para a televisão.

Entre os programas de maior influência da televisão estão os telejornais, seja em termos comerciais, seja em termos de impacto e credibilidade. Os telejornais estão entre as maiores audiências dos canais e possuem os intervalos comerciais mais caros. No caso da TV Globo, canal de maior audiência no Brasil desde a década de 1970, o JN é apontado pela emissora como principal programa (MEMÓRIA GLOBO, 2004; BIAL, 2004; BARBOSA; RIBEIRO, 2005), que apesar de não representar a maior audiência do canal (na média, a novela das 21 horas tem audiência superior), possui o intervalo comercial mais caro da TV brasileira, no qual um anúncio de 30 segundos custava, a preço de tabela, R\$ 630.000,00 no começo de 2014.

No entanto, apesar desses números, o cenário está longe do ideal para a TV Globo. O JN tem perdido audiência sistematicamente. Se na década de 1970 e 1980 era comum o telejornal apresentar índices de audiência superiores a 70 pontos, a virada do milênio também inverteu a lógica da audiência. Desde janeiro de 2000, a maior média mensal da audiência foi $44,2 \%$, registrada em junho de 2004. Comparativamente em outubro de 1985, a média foi 62 pontos. Considerando a média anual, o maior índice registrado desde 2000 foi em 2004, quando obteve 39,8 pontos. Em 1989, era 60 pontos.

Nesse sentido, investigar e quantificar estatisticamente o comportamento da audiência do JN nesse século são os propósitos deste artigo. Para tanto, pretende mostrar o quanto é a queda acumulada ao longo dos anos, se ela é constante ou se há momentos de recuperação, comparar com a audiência dos outros canais no mesmo horário e com a quantidade de TVs ligadas, projetar cenários futuros para o telejornal e analisar os 
impactos no telejornalismo. Para responder a essas questões, foram analisados os índices de audiência do $\mathrm{JN}$ entre os anos 2000 a 2013. A partir da média diária obteve-se a média mensal e a partir dessa, a média anual.

É preciso ressaltar que a quantificação da audiência tradicionalmente não compõe os estudos de recepção na área do jornalismo. A fruição da notícia e como as pessoas a decodificam são temas mais comumente estudados do que análise de estatísticas do comportamento do público (SCHUDSON, 2000). Para Livingstone (1998), a audiência é uma categoria implícita nos estudos de recepção em jornalismo, mas com preocupações marginais. Madianou (2009, p. 326), ao analisar as pesquisas de recepção em jornalismo, afirma que "as conclusões são extraídas com certeza a partir da relação entre o conteúdo abstrato da mensagem e respostas individuais ou agregadas igualmente abstratas". A autora explica ainda que até o termo "audiência" é evitado por certos pesquisadores, por estar relacionado ao consumo.

No entanto, como este artigo demonstra, do ponto de vista da televisão comercial, a quantificação da audiência é um dos elementos fundamentais para a sobrevivência do telejornalismo. Se por um lado, a queda de audiência pode refletir uma crise de identidade e de credibilidade, por outro, diminui o impacto que a televisão sempre deteve como indutora de agendas de discussão.

\section{A importância da audiência para a televisão comercial}

“Audiência" é um termo definido por McQuail (1997) como o coletivo das pessoas que recebem informações no modelo sequencial do processo de comunicação de massa, são aquelas que assistem televisão, escutam rádio e leem jornais e revistas. Bermejo (2007) atualiza o termo "audiência" e inclui também os usuários da internet. Apesar de questionar se a internet pode ser considerada um meio de comunicação de massa, o autor acredita que a palavra audiência é a que melhor representa os consumidores da informação on-line.

Os estudos sobre o comportamento da audiência e a forma como acontece a recepção dos conteúdos datam da origem do uso comercial dos meios de comunicação. Larrañaga (1998) explica que todos os sistemas comerciais de comunicação de massa dependem da quantificação da audiência para estabelecer os preços da publicidade. No caso específico da televisão, a quantidade percentual de pessoas assistindo a determinado canal ou programa é o principal meio para definir o custo dos anúncios e patrocínios. Cruz (2008) simplifica o modelo de negócios da TV aberta comercial afirmando que as emissoras de TV simplesmente vendem índices de audiência para os anunciantes, 
abstraindo a produção e a recepção dos programas. Quanto maiores os índices, maiores os preços.

Estes índices são medidos no Brasil pelo Instituto Brasileiro de Opinião Pública e Estatística (Ibope), empresa privada que comercializa os dados referentes à audiência para emissoras de TV e agências de publicidade. A coleta dos dados é feita por uma amostra estatística, em que cada residência recebe de um a quatro audímetros (também chamados de people meters), que mapeia o canal sintonizado. A quantidade de pessoas diante da TV também faz parte da medição. No entanto, essa informação é fornecida pelos próprios telespectadores, através do controle remoto do audímetro.

Nessa amostra é possível projetar estatisticamente a quantidade total da população que está assistindo determinado programa (MCQUAL, 1997; JAUSET, 2000). Os dados são disponibilizados pelo Ibope em forma de pontos percentuais. Ou seja, se na medição da audiência determinado programa obteve 10 pontos de audiência, significa que $10 \%$ da amostra assistiu ao programa, o que, pela projeção, corresponde a $10 \%$ da população.

Atualmente, toda análise comercial da audiência da TV brasileira está restrita a São Paulo, que possui uma amostra de 740 residências. Apesar da audiência ser medida em mais 13 cidades, os dados mais importantes, e utilizados na comercialização dos espaços publicitários, são da região metropolitana de São Paulo. Além do peso econômico da cidade de São Paulo, que possui o terceiro maior Produto Interno Bruto (PIB) do país (atrás apenas do PIB nacional e do estado de São Paulo), nessa cidade estão localizadas as maiores agências de publicidade e todas as cabeças de rede das emissoras comerciais. A única exceção é a TV Globo, cuja cabeça de rede fica no Rio de Janeiro, mas que mantém boa parte das produções e do departamento comercial em São Paulo.

Por essa razão, o presente estudo também se baseia nos dados de audiência da região metropolitana de São Paulo.

\section{Evolução da audiência do JN entre 2000 e 2013}

A Tabela 1 apresenta as médias anuais da audiência do JN, o total de TVs ligadas no horário, em que o programa foi ao ar e a participação do JN. No período, a audiência média anual do JN caiu de $39,2 \%$ em 2000 para $26 \%$ em 2013. São 13,1 pontos percentuais a menos em 14 anos. Este número corresponde relativamente a 33,5\% da audiência, o que significa que em 14 anos o JN perdeu 1/3 da audiência na TV aberta.

\footnotetext{
$90 \frac{\text { Comunicação \& Inovação, PPGCOM/USCS }}{\text { v. 16, n. } 32 \text { (87-102) set-dez } 2015}$
} 
Tabela 1: Audiência, participação e total de TVs ligadas no horário do Jornal Nacional ${ }^{1}$

\begin{tabular}{|c|c|c|c|}
\hline Ano & JN & TTL & Share JN \\
\hline 2000 & 39,2 & 69,2 & 56,6 \\
\hline 2001 & 37,8 & 66,7 & 56,6 \\
\hline 2002 & 36,6 & 66,4 & 55,2 \\
\hline 2003 & 36,6 & 64,6 & 56,7 \\
\hline 2004 & 39,8 & 64,3 & 61,9 \\
\hline 2005 & 35,8 & 65,3 & 54,8 \\
\hline 2006 & 36,4 & 67,1 & 54,3 \\
\hline 2007 & 34 & 63,2 & 53,8 \\
\hline 2008 & 32,4 & 63,8 & 50,9 \\
\hline 2009 & 30,9 & 61,3 & 50,4 \\
\hline 2010 & 29,8 & 60,6 & 49,3 \\
\hline 2011 & 32 & 61,1 & 52,4 \\
\hline 2012 & 28,2 & 58,2 & 48,5 \\
\hline 2013 & 26 & 56,1 & 46,4 \\
\hline
\end{tabular}

Em 2004, o JN obteve a maior audiência do período, com 39,8 pontos. Desde aquele ano, a audiência tem caído em todos os anos, exceto em 2006, quando subiu 0,6 pontos, e 2011, quando teve um aumento de 2,2 pontos. Além da audiência ter caído nesse período, a participação também diminuiu. Em 2000, 56,6\% das TVs ligadas no horário do JN estavam sintonizadas no programa. Já em 2013, esse número baixou para 46,4\%.

No mesmo período, a quantidade de TVs ligadas no horário do JN caiu de $69 \%$ para $56 \%$, o que corresponde a 13 pontos percentuais, número próximo da queda de audiência do telejornal. Em outras palavras, os 13 pontos percentuais que deixaram de assistir ao JN desligaram a televisão. Ao contrário da audiência do JN, que teve oscilações nesses 14 anos, no caso das TVs ligadas observa-se uma queda constante, exceto em 2006, quando o número ficou em 67\%, dois pontos percentuais a menos do que em 2000 , porém 1,8 superior a 2005 . Desde aquele ano, o número vem baixando, chegando a $56 \%$ em 2013.

\section{Variações mensais}

Considerando todos os 168 meses analisados, não foram identificados padrões de variação em torno de eventos-chave, como eleições, transmissões esportivas ou coberturas

1 Esta tabela e os gráficos apresentados a seguir foram elaborados pelos autores a partir dos índices de audiência medidos pelo Ibope. 
especiais, como catástrofes naturais ou atentados terroristas. A única exceção ocorreu em setembro de 2001, quando a audiência média do mês foi a maior do ano, 41,4\%, impactada pela cobertura do atentado às Torres Gêmeas, nos Estados Unidos. A edição do dia 11 de setembro teve audiência recorde no ano, com 53 pontos e 74 de participação. Nos dias seguintes a audiência alta se repetiu, ficando na casa dos 50 pontos nos dias 12 e 13 .

Nos demais casos, a audiência média mensal varia dentro de uma margem de 2 pontos percentuais, acima ou abaixo da média, não sendo possível identificar padrões de comportamento. Por exemplo, nos meses de setembro e outubro dos anos pares, quando ocorrem as eleições, os índices estão dentro dessa variação de dois pontos (tanto acima, quanto abaixo da média anual), o que significa um impacto insignificante das eleições (cobertura e horário eleitoral) na audiência do programa. O mesmo acontece nos meses de junho e julho de 2002, 2006 e 2010, ano de Copa do Mundo. No caso das Olimpíadas, tal fenômeno se repete.

Único padrão identificado na análise mensal dos dados foi uma queda considerável da audiência nos meses de dezembro. Dos 14 anos analisados, em 10 a pior média mensal foi em dezembro. Apenas em 4 anos as piores audiências foram registradas em outros meses: 2000 (abril, 37,5\%), 2006 (janeiro, 30,1\%), 2009 (fevereiro, 26,6\%) e 2010 (fevereiro, $26,1 \%$ ). Nos demais anos, a audiência em dezembro foi: 2001: 32,2\%; 2002: 29,4\%; 2003: 32,9\%; 2004: 35,5\%; 2005: 30,0\%; 2007: 30,8\%; 2008: 30,6\%; 2011: 29,3\%; 2012: 22,2\%; 2013: 21,0\%.

Por outro lado, apenas em dois anos a audiência em dezembro foi superior a média anual. Em 2000, com 0,3 pontos, e em 2010, com 1,8 pontos. A maior diferença ocorreu em 2002, quando a média anual do telejornal foi $36,6 \%$ e a média mensal de dezembro 29,4\%. Este também foi o ano com a maior diferença na média das TVs ligadas, com média anual de 66,4 e mensal de 56,2 .

\section{Comparativo com outros canais}

O fenômeno da queda de audiência no horário do JN não está restrito à TV Globo. Praticamente todos os canais tiveram queda de audiência no horário do telejornal. Apenas a TV Record registra em 2013 (6,3\%) índices superiores aos de $2000(6,0)$, conforme apresentado no Gráfico 1.

Nesse período, chama atenção o crescimento dos outros canais e outros dispositivos conectados à televisão (OCN + OPA), que aumentou de 7,8 para 12,5. É importante ressaltar uma variação negativa entre 2000 e 2001 (7,8 para 3,1), fruto de uma mudança 
metodológica na medição. Considerando o período compreendido entre 2001 e 2013, a audiência da TV fora dos canais abertos aumentou mais de 300\%.

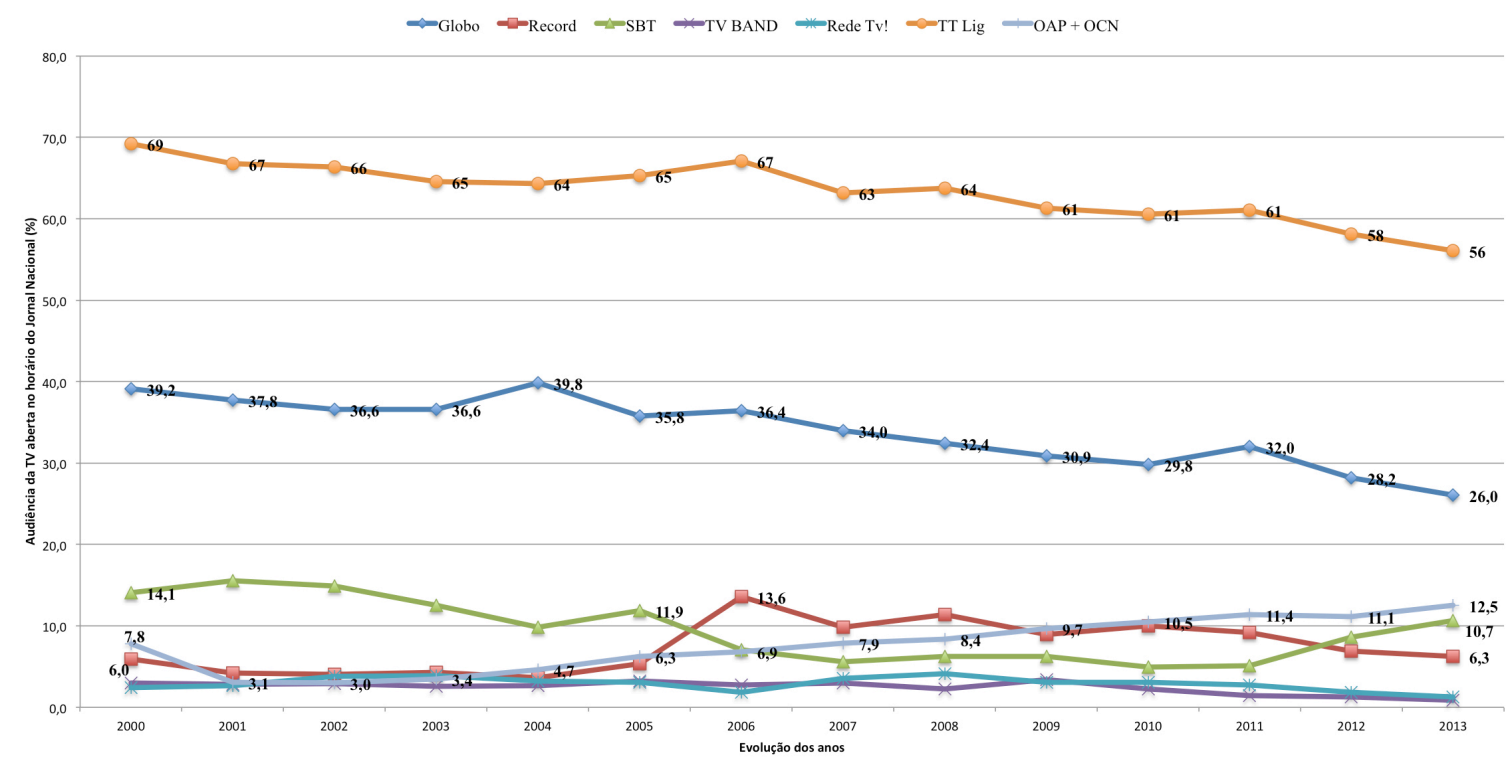

Gráfico 1: Comparativo da audiência do JN com os demais programas do horário e quantidade de TVs ligadas

\section{Comparação com a audiência geral da TV brasileira}

A queda da audiência no horário do JN está em sintonia com tendências identificadas no comportamento de toda televisão brasileira. Analisando os dados da audiência diária, disponibilizados pelo Ibope, de 2000 a 2013, percebe-se que a TV tem menos audiência em todos os horários.

O Gráfico 2 mostra a variação da soma da audiência dos cinco principais canais, cuja audiência é superior a um ponto percentual, na Grande São Paulo, e a quantidade de TVs ligadas. Fazendo uma análise por períodos, os índices variaram pouco entre 2000 e 2006 . A audiência somada dos cinco principais canais caiu de 39,37 para 38,75\%, uma queda absoluta de 0,62 pontos percentuais, ou 1,6\%. Já entre 2006 e 2013 há uma queda acentuada na audiência da TV aberta brasileira. Se em 2006 os cinco principais canais comerciais tinham juntos 38,75\% da audiência, em 2013 ela caiu para 28,26\%. São 10,49 pontos percentuais a menos. Em termos relativos, $27 \%$ (mais de um quarto da audiência) deixou de ver um dos cinco canais de TV aberta. Considerando todo período de análise, a queda foi superior a 28\%.

Analisando a quantidade de TVs ligadas no período, percebe-se que há uma queda nos números, apesar das oscilações durante os 14 anos estudados. No primeiro ano da análise, em média 45,45\% das TVs ficavam ligadas no período entre 7 horas e meia-noite, 
entretanto esse número caiu para 41,70\% em 2013. No entanto, é preciso considerar três oscilações para cima. A primeira ocorreu entre 2001 e 2002, após uma queda de mais de 3 pontos percentuais na quantidade de TVs ligadas em 2001.

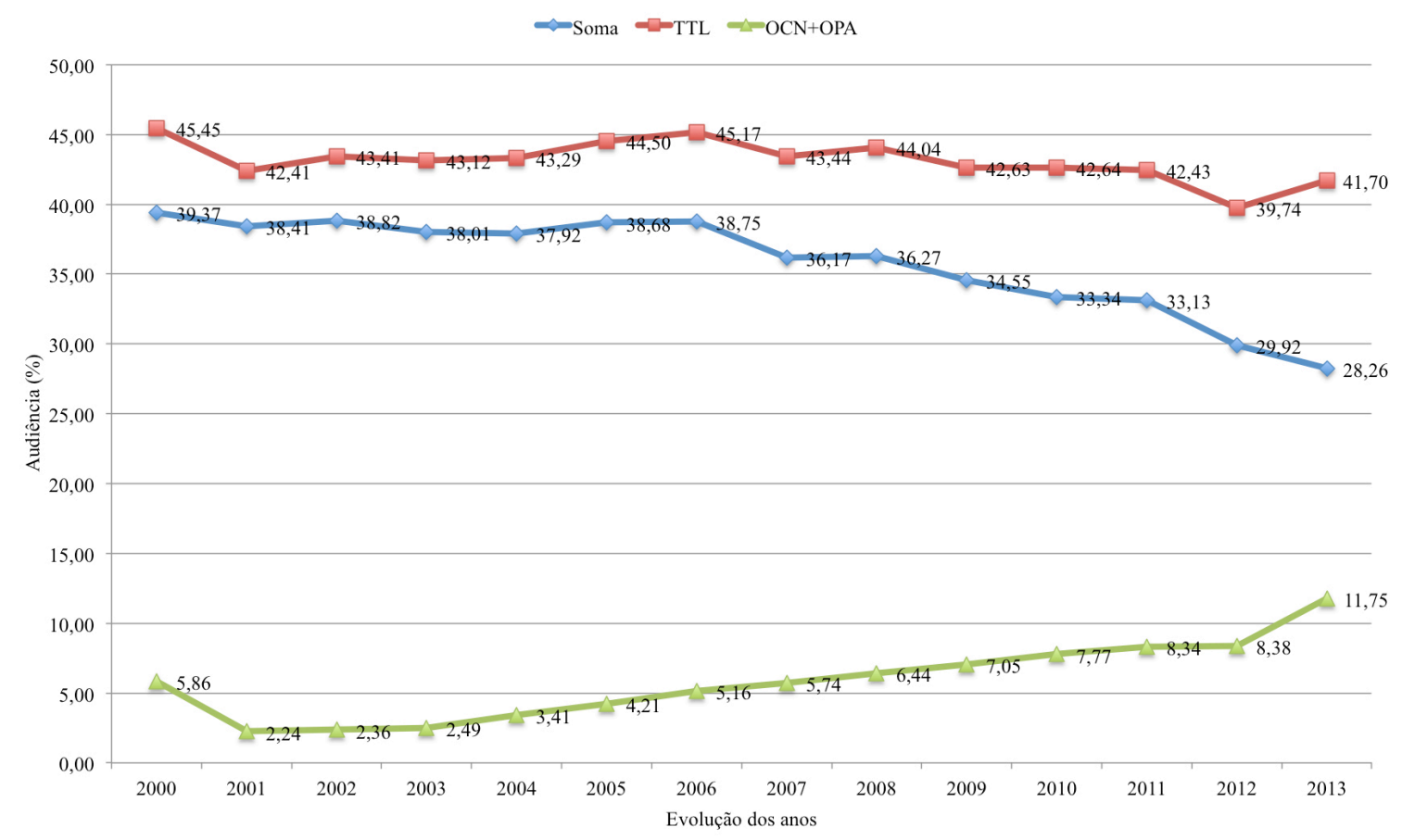

Gráfico 2: Comparativo entre a soma dos canais com mais de 1\% de audiência mensal média com a quantidade de TVs ligadas e com outros canais/dispositivos

$\mathrm{Na}$ segunda, em 2006, a quantidade de TVs ligadas se aproximou dos índices medidos em 2000, com 45,17\% dos aparelhos ligados. Esse número oscilou para baixo a partir daquele ano até atingir 39,74\% em 2012, menor índice já registrado pelo Ibope. Em 2013 o número subiu para 41,70\%, diminuindo um pouco a perda de telespectadores. Apesar desse aumento, a televisão brasileira perdeu 8,25\% dos aparelhos ligados nos últimos 14 anos. Trata-se de um número inferior ao registrado no horário do JN, o que mostra que à noite uma quantidade maior de pessoas está deixando de ver TV do que durante o dia.

Analisando ainda o Gráfico 2, repete-se o crescimento dos outros canais e outros dispositivos (OCN + OPA). Em 2000, 5,86\% das TVs assistiram a conteúdos de TV fechada. Esse número caiu para 2,24\% no ano seguinte, o que também pode ser atribuído a mudanças metodológicas na medição do OCN e da TV paga. A partir de 2002, o índice foi crescendo ano após ano, com média superior a um ponto percentual a partir de 2008 . O maior crescimento foi verificado no último ano da análise, quando a quantidade de TVs 
sintonizadas em outros canais ou utilizada com outros dispositivos oscilou de 8,38 para $11,75 \%$, um aumento superior a $40 \%$.

\section{Projeção da audiência do Jornal Nacional para os próximos 14 anos}

Com o objetivo de compreender o que poderá acontecer futuramente com a audiência do JN, faz-se a seguir uma projeção dos índices para os próximos 14 anos.

Magalhães e Lima (2011) explicam que a projeção é um recurso estatístico que visa antecipar o comportamento de determinadas variáveis dentro de cenários conhecidos. Dessa forma, busca-se compreender o comportamento futuro das variáveis analisando seus dados históricos. Ou seja, extrapola-se para o futuro as relações e comportamentos já observados entre as variáveis no passado.

De forma simplificada, o ponto de partida desse processo é a análise da regressão, através de um diagrama de dispersão, que consiste em um modelo matemático que relaciona o comportamento de uma variável Y com outra X, permitindo inferir, projetar, ou prever uma linha futura a partir de uma base histórica de dados.

Em termos estatísticos, em uma análise de regressão, traça-se uma linha que minimiza a soma dos erros quadráticos entre o valor estimado e o dado observado. Da mesma forma, a reta resultante deverá ser aquela que torna mínima a soma dos quadrados das distâncias da reta em relação aos pontos experimentais. Os erros são as diferenças entre os dados reais e aqueles preditos pelo modelo. Além de projetar, o segundo maior uso da análise de regressão é entender a relação entre as variáveis.

No caso do presente estudo, as variações dos índices de audiência dos últimos 14 anos são dispersos no diagrama, onde o eixo X corresponde aos anos. Trata-se da variável controlada pelo observador, chamada, na estatística, de "independente". Já o eixo Y representa os índices de audiência e corresponde à variável dependente. Uma linha, que representa a análise da regressão, identifica padrões de comportamento entre os dados, o que permite gerar as projeções.

Nos Gráficos 3 e 4, as análises da regressão são apresentadas pelas retas entre os anos 2000 e 2013. Já as projeções são feitas pela continuidade das retas, a partir dos padrões identificados anteriormente.

Ao mostrar em um gráfico cartesiano os pares de informação referente a cada momento observado durante um período, obtém-se um conjunto de pontos definidos pelas coordenadas X e Y de cada ponto. Esse conjunto definirá uma reta ou direção que caracterizará o padrão de relacionamento entre X e Y. Caso se observe uma tendência, ou um 
eixo linear, nesse conjunto de pontos cartesianos, tem-se o que é chamado estatisticamente de "regressão linear". É o caso do comportamento dos índices de audiência televisiva. A relação entre as variáveis será direta, ou positiva, quando os valores de Y aumentarem em decorrência da elevação dos valores de $\mathrm{X}$, e será inversa, ou negativa, quando os valores de $\mathrm{Y}$ variarem inversamente em relação aos de $\mathrm{X}$.

Com os dados de audiência referentes ao período de 2000 a 2013, fez-se uma projeção para os próximos 14 anos, considerando os dados mais importantes para a compreensão do cenário da audiência do $\mathrm{JN}$ : a audiência média do programa, a audiência não relacionada à TV aberta, o que inclui a TV paga e outros dispositivos conectados à TV (soma de OCN com OPA), e o total de aparelhos ligados (TTL).

As projeções foram feitas considerando dois diferentes cenários. O uso de cenários é útil para antever o que pode acontecer se um conjunto diferente de previsões se confirmar (BUARQUE, 2003).

No primeiro cenário, considerou-se a oscilação da audiência durante os 14 anos. Esse é considerado o cenário "provável" e mostra o comportamento dos índices de audiência caso a média dos últimos 14 anos se mantenha.

Como foi identificada uma tendência de queda mais acentuada a partir de 2004, em comparação com os anos anteriores, optou-se por fazer outra projeção da audiência, considerando a possibilidade de manutenção da tendência de queda identificada a partir daquele ano. Esse é o cenário "pessimista".

O cenário é apresentado no Gráfico 3. No primeiro caso, foi aplicada a curva de regressão nos 14 anos em análise. As quedas da audiência e participação JN, e da quantidade de TVs ligadas, se mantêm. Caso se mantenham as características das quedas dos últimos 14 anos, em 2027 a audiência do JN será de 14,5\%, com participação de 36,8\%. A quantidade de TVs ligadas no horário do programa será de $47 \%$. 


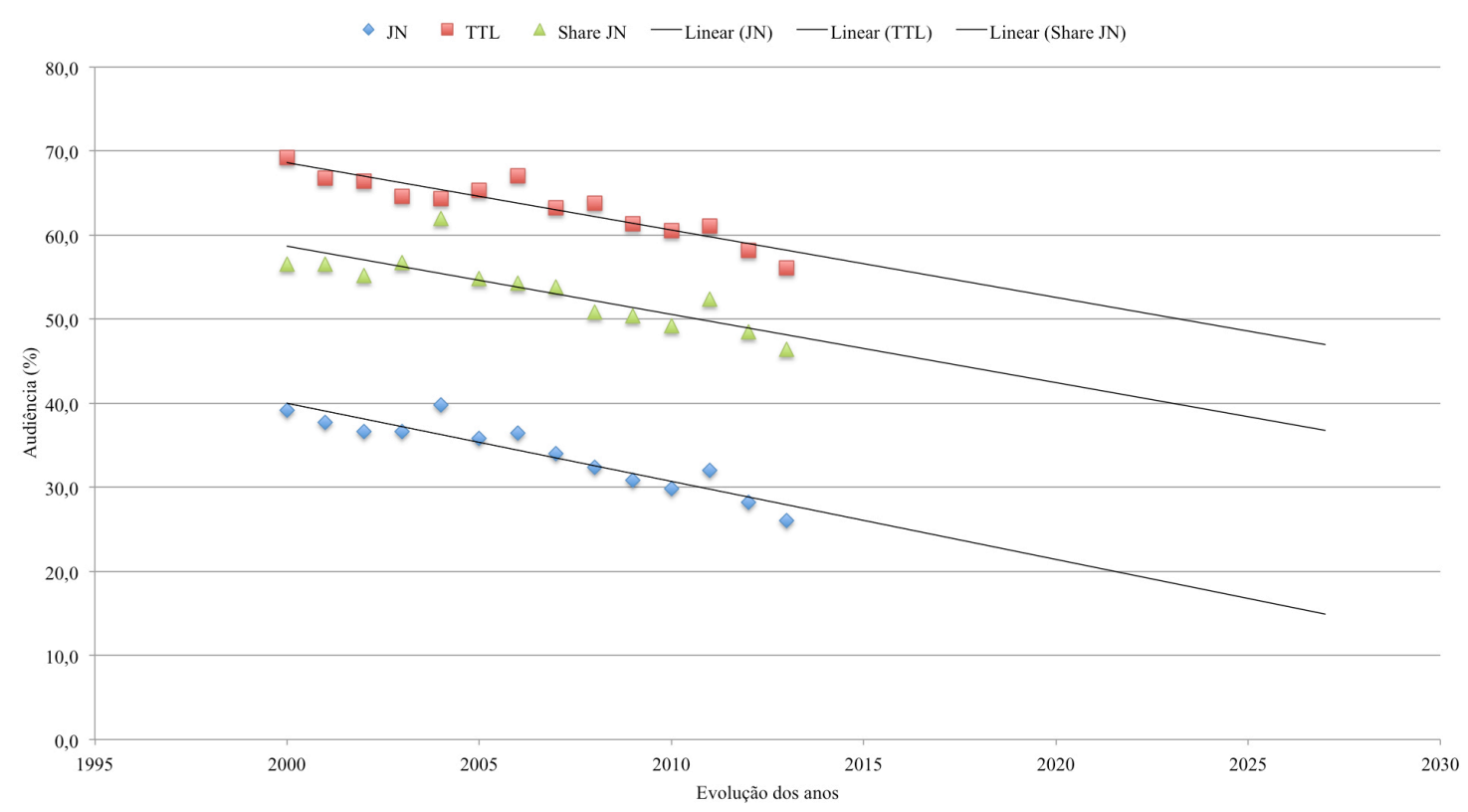

Gráfico 3: Projeção para o cenário "provável”

Como se pode observar no Gráfico 3, nem todos os pontos estão sobre a reta de regressão calculada, uma vez que ela representa uma aproximação da realidade, útil para indicar tendências. A exatidão da projeção depende de quão precisa a reta de regressão é, o que torna necessário calcular o quanto os valores estão variando em torno dessa linha - podendo afetar a projeção. Para isso são utilizados dois índices, o erro padrão e o coeficiente de correlação. O primeiro informa a variação da distância dos pontos em relação à reta, correspondendo à amplitude da variação que pode ocorrer na projeção. O segundo calcula o quanto uma variável independente prevê a dependente. Valores iguais ou próximos a 1 (relação direta) ou -1 (relação inversa) indicam que existe uma forte relação entre as variáveis. Coeficientes de correlação próximos de zero indicam que existe pouco relacionamento entre as variáveis, tornando a projeção imprecisa (MAGALHÃES; LIMA, 2011).

O erro padrão e o coeficiente de correlação do cenário provável foram, respectivamente, audiência do JN: 1,6 e -0,9; participação: 1,5 e -0,9; total de aparelhos ligados: 2,4 e -0,8. Identifica-se uma oscilação mais elevada em torno da reta na audiência, o que significa que pode ocorrer variações dessa magnitude também na projeção. Já os índices de correlação estão próximos a -1, o que indica uma previsão confiável dessas variáveis.

Considerando o cenário "pessimista" (Gráfico 4), onde se mantém a tendência identificada de 2004 a 2013, a audiência do JN fica em 8,6\% em 2027, com participação de 28,9\%. Trata-se de um cenário inimaginável no contexto mercadológico da televisão brasileira, 
apesar de possível, e até provável, estatisticamente. Nesse cenário, a quantidade de TVs ligadas em 2027 será 43,4\%.

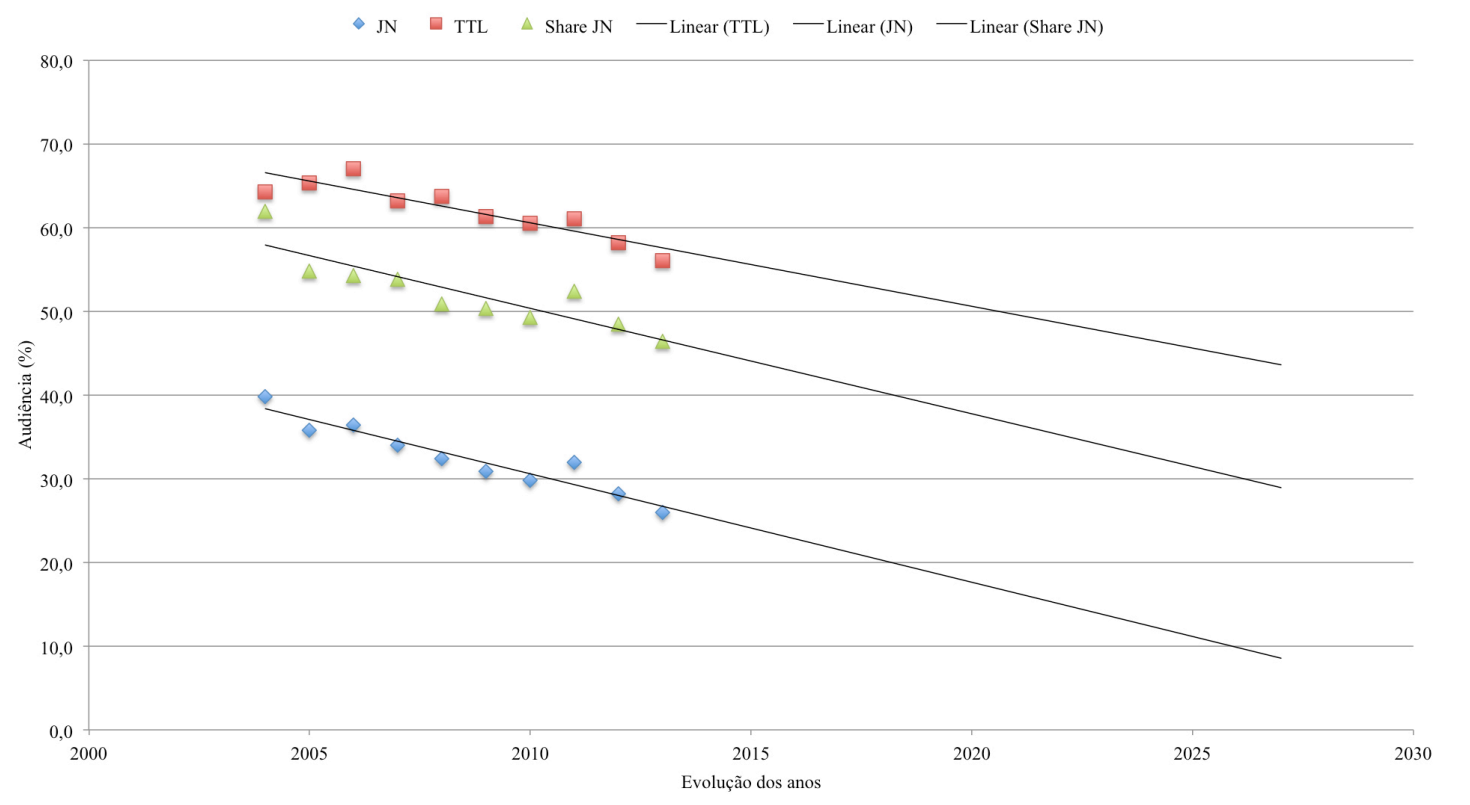

Gráfico 4: Projeção para o cenário "pessimista"

O erro padrão e o coeficiente de correlação foram, respectivamente, audiência do $\mathrm{JN}$ : 1,3 e -1,0; participação: 1,5 e -0,9; total de aparelhos ligados: 2,2 e -0,9. Esses dados indicam uma previsão mais confiável do que a anterior, com oscilações menores em torno da curva e índices de correlação que conseguem prever as variáveis dependentes. Trata-se do cenário que tem os indicativos estatísticos mais próximos da confiabilidade. Esses índices estão relacionados às variáveis dependentes, mapeadas ao longo do período analisado. Como será discutido nas próximas seções, fatores externos podem interferir nesses cenários.

\section{Análise dos valores absolutos}

Como visto nas seções anteriores, a audiência do JN, assim como de toda televisão brasileira, está caindo ano após ano. No entanto, o aumento da população e um maior acesso à televisão podem distorcer esses dados. Uma queda percentual pode, na realidade, corresponder, em termos absolutos, a um aumento no total de pessoas diante da TV. Por isso, torna-se necessário investigar também os números absolutos da audiência, projetados pela medição do Ibope.

Considerando os números absolutos, em 2000 cada ponto da audiência correspondia a 162.465 pessoas. Já em 2013, esse número aumentou para 185.814 indivíduos. 
Dessa forma, em 2000 a audiência do JN era 39,2\% da população, o que corresponde a um total de 6,4 milhões de pessoas. Já em 2013, esse número baixou para $26 \%$ da população, o que equivale a 4,8 milhões de pessoas. Ou seja, em números absolutos, a audiência do $\mathrm{JN}$ também diminuiu.

É preciso considerar que a amostra da pesquisa aumentou nesses 14 anos. Em 2000, a amostra estava restrita à cidade de São Paulo e algumas cidades vizinhas, e representava uma população de 16 milhões de habitantes. Em 2013, a amostra foi expandida para toda a região metropolitana de São Paulo, compreendendo quase 19 milhões de habitantes. Apesar dessa mudança na amostra não afetar os dados estatísticos, ela influencia na projeção para o todo, gerando uma dimensão maior para cada ponto de audiência. Mesmo desconsiderando esse aumento na amostra, a audiência do JN caiu 24\%. Trata-se de uma queda inferior à apontada pelos índices do Ibope (33,7\%), mas confirma a tendência de menos pessoas diante da TV.

\section{Conclusão}

Mantendo-se o cenário dos últimos 14 anos, a tendência é queda de audiência do JN, especificamente, e da televisão aberta, em geral, se acentuar. As projeções são desanimadoras para quem trabalha com telejornalismo. No entanto, mudanças e inovações nas programações, na gestão das emissoras, na administração de recursos humanos ou qualquer mudança estrutural no mercado podem alterar esses cenários. Do ponto de vista estatístico, as projeções apontam que, se nenhuma mudança considerável ocorrer, um destes cenários tende a se concretizar.

Um item que ainda carece de maiores estudos é o impacto da queda da audiência no jornalismo. Estudos têm demonstrado que existe migração de audiência da televisão para a internet, não apenas quantitativos, mas também qualitativos (JAFFE, 2008; LIEBOWITZ; ZENTNER, 2012; BECKER, 2011; BECKER; GAMBARO; LEMOS FILHO, 2015). Se confirmada essa hipótese, a queda de audiência pode se acentuar, uma vez que no Brasil menos da metade da população usa a internet atualmente (BRASIL, 2014). Com o crescimento do número de pessoas usando a rede e com o aumento da velocidade de transferência dos dados, algo que ainda é um fator crítico no Brasil, a migração da audiência deverá continuar.

Outro fator relevante é a mudança do referencial de qualidade da informação. Durante décadas o JN foi considerado o principal meio de informação do país. Com a disseminação da internet e o acesso a outras fontes, os telejornais estão se transformando em mais um meio, correndo o risco de deixarem de ser o principal. 
No campo do consumo de informação é evidente a diversificação e modificação dos hábitos por parte da audiência, o que afeta a forma como as pessoas se relacionam com a informação e com a notícia. A relação do valor que as pessoas dão para a informação e a credibilidade despertada pela notícia tem sido foco de estudo mundo afora. A percepção de que as notícias variam em importância e intepretação de acordo com crenças e gostos pessoais foi apontada, entre outros, por Bird (1992), Liebes (1997) e Kitzinger (1993). Já Morley (1980) concluiu que a classe social e o lugar onde as pessoas vivem afeta a percepção de valor sobre as notícias. Além disso, Philo (1990) e Madianou (2007) apontam que a existência de fontes alternativas de informação e o grau de exposição e dependência de determinado veículo também têm impactos na fruição da notícia.

Todos esses estudos, realizados em épocas e países diferentes, têm em comum o fato de apontar que quanto maior a opção de acesso às notícias, menor é a possibilidade de um único veículo dominar a atenção e a credibilidade. A possibilidade de cotejar notícias entre diferentes veículos e diferentes mídias desperta um senso crítico mais apurado, o que chega a pôr em xeque determinadas instruções ideológicas de determinados veículos.

Esse processo é reforçado e facilitado com as tecnologias digitais e a capacidade da audiência se conectar em rede, o que acentua a mudança de percepção do valor da informação. Se há algum tempo a televisão detinha o monopólio da transmissão e produção da informação e da notícia, com impactos quantitativos na audiência, atualmente ela compete com as mídias on-line, apesar de limitadas a parte da população, e os dispositivos digitais portáteis que tornam os processos mais simples e acessíveis para produção, edição e publicação de conteúdos audiovisuais pela própria audiência e profissionais independentes.

Essa perda de valor como produto audiovisual televisivo reflete outro debate importante para o jornalismo: a credibilidade da informação, um dos importantes valores creditados ao noticiário para atrair e manter a fidelização da audiência. Philo (1990) afirma que a crença em um quadro de mídia dominante foi maior entre aqueles que eram mais dependentes dos meios de comunicação. Além disso, Madianou, (2005) mostra que quando as pessoas conhecem algo sobre o tema das notícias, a percepção e interpretação mudam. Ou seja, novamente a experiência pessoal interfere na recepção.

O JN, segundo Lins da Silva (1985), mostrou que quanto mais informações a pessoa dispõe, mais ela questiona as notícias do telejornal: "a comparação entre o que está nas telas e o que está nas ruas, nas casas dos espectadores é, por sinal, o método mais simples de questionar os telejornais e, dependendo do encaminhamento que houver, inicia a formação do senso crítico em relação à TV" (Ibidem, p. 88).

Como visto anteriormente, o acesso a mais informações pela internet reforça esse cenário. Quando o único acesso à informação era o JN, o telespectador tinha poucos 
elementos de checagem e de confirmação da mensagem que recebia. Com a possibilidade do acesso à informação on-line, além da discussão acessível e facilitada pelas redes sociais, surgem elementos novos de confirmação da veracidade diversificando ainda mais os olhares perante a construção da realidade retratada pelo telejornal. Esse processo é normal na apreensão da informação, como mostrou Lins da Silva (1985), mas com a migração da audiência da TV para a internet, choques de visão do que é real e o que é mal mediado pelos gatekeepers dos telejornais se tornam cada vez mais frequentes.

Essa mudança de referencial sobre qualidade da informação tende a se acentuar. Os telejornais, apesar do aumento da resolução e da qualidade da imagem, enfrentam cada vez mais problemas em "mostrar o real" e sentem a necessidade de buscar outras formas de criar e manter laços de proximidade e familiaridade com a audiência para assim sustentar a fidelização do seu público.

\section{Referências}

BARBOSA, M.; RIBEIRO, A. P. G. Telejornalismo na Globo: vestígios, narrativa e temporalidade. In: BRITTOS, V. C.; BOLAÑO, C. R. S. (orgs.). Rede Globo: 40 anos de poder e hegemonia. São Paulo: Paulus, 2005, p. 205-223.

BECKER, V. Ambiente de medição da audiência para TV digital. 2011. Tese (Doutorado em Sistemas Eletrônicos) - Escola Politécnica, Universidade de São Paulo, São Paulo, 2011. Disponível em: <http://www.teses.usp.br/teses/disponiveis/3/3142/tde-01112011-121109/>. Acesso em: 2015-11-09.

BECKER, V., GAMBARO, D., SOUZA FILHO, G.L. Junio de 2015. O impacto das mídias digitais na televisão brasileira: queda da audiência e aumento do faturamento. Palabra Clave 18 (2), 341-373. DOI: $10.5294 /$ pacla.2015.18.2.3

BERMEJO, F. The internet audience: Constitution \& measurement. New York: Peter Lang, 2007.

BIAL, P. Roberto Marinho. Rio de Janeiro: Jorge Zahar, 2004.

BIRD, E. S. For inquiring minds: a cultural study of supermarket tabloids. Knoxville: University of Tennessee, 1992.

BRASIL. Secretaria de Comunicação Social. Pesquisa brasileira de mídia 2014: hábitos de consumo de mídia pela população brasileira. Brasília: Secom, 2014.

BUARQUE, S. C. Metodologia e técnicas de construção de cenários globais e regionais. Texto para discussão, 939. Brasília: IPEA, 2003.

BUCCI, E. Prefácio. In: Brasil em tempo de TV. São Paulo: Boitempo, 1997, p. 11-38.

CRUZ, R. TV digital no Brasil: tecnologia versus política. São Paulo: Senac, 2008.

HOINEFF, N. A nova televisão. Rio de Janeiro: Relume Dumará, 2001. 
JAFFE, J. O declínio da mídia de massa: Por que os comerciais de TV de 30 segundos estão com os dias contados? São Paulo: Mbooks, 2008.

JAUSET, J. A. La investigación de audiencias en televisión: fundamentos estadísticos. Barcelona: Paidós, 2000 .

KITZINGER, J. Understanding AIDS: researching audience perceptions of the acquired immune deficiency syndrome. In: ELDRIDGE, J. (Ed.). Getting the message: news, truth and power. London: Routledge, 1993, p. 271-304.

LARRAÑAGA, G. M. La batalla por las audiencias. In: XIV CONGRESO DE ESTUDIOS VASCOS. SOCIEDAD DE LA INFORMACIÓN. Donostia: Eusko Ikaskuntza, 1998, p. 91-95.

LIEBES, T. Reporting the Israeli-Arab conflict: how hegemony works. London: Routledge, 1997.

LIEBOWITZ, S. J., ZENTNER, A. Clash of the titans: does internet use reduce television viewing? The Review of Economics and Statistics, v. 94, n. 1, p. 234-245, feb. 2012.

LINS DA SILVA, C. E. Muito além do Jardim Botânico: um estudo sobre a audiência do Jornal Nacional da Globo entre trabalhadores. São Paulo: Summus, 1985.

LIVINGSTONE, S. Audience research at the crossroads: the "implied audience" in media and cultural theory. European Journal of Cultural Studies, v. 1, n. 2, p. 193-217, 1998.

MACHADO, A. Máquina e imaginário. 2. ed. São Paulo: Edusp, 1996.

MADIANOU, M. Mediating the nation: news, audiences and the politics of identity. London: UCL Press; Routledge, 2005.

Shifting identities: banal nationalism and cultural intimacy in Greek television news and everyday life. In: MOLE, R. (Ed.). Discursive constructions of identity in European politics. London: Palgrave, 2007, p. 95-118.

Audience reception and news in everyday life. In: JORGENSEN, K. W.; HANITZSCH, T. The handbook of journalism studies. New York: Taylor \& Francis, 2009, p. 324-340.

MAGAlhãES, M. N.; LIMA, A. C. P. Noções de probabilidade e estatística. São Paulo: Edusp, 2011.

MEMÓRIA GLOBO. Jornal Nacional: a notícia faz história. Rio de Janeiro: Jorge Zahar, 2004.

MORLEY, D. The Nationwide audience: structure and decoding. Television monograph. London: BFI, 1980.

McQUAIL, D. Audience analysis. London, UK: Sage, 1997.

PHILO, G. Seeing and believing: the influence of television. London: Routledge, 1990.

PROJETO INTER-MEIOS. Relatórios de Investimento. 2013. Disponível em: <http://www.projetointermeios.com.br/relatorios-de-investimento>. Acesso em: 3 nov. 2014.

SCHUDSON, M. The sociology of news production revisited (again). In: CURRAN, J.; GUREVITCH, M. (Eds.). Mass media and society. 3. ed. London: Edward Arnold, 2000, p. 175-200. 